\title{
An Alternative Stiffening Method for Rigid CHS L-Joints
}

\author{
Niall Holmes, Darran Kierans, and Patrick Crean \\ School of Civil and Structural Engineering, Dublin Institute of Technology, Bolton Street, Dublin 1, Ireland \\ Correspondence should be addressed to Niall Holmes; niall.holmes@dit.ie \\ Received 17 May 2016; Revised 8 June 2016; Accepted 12 June 2016 \\ Academic Editor: Lucio Nobile
}

Copyright (C) 2016 Niall Holmes et al. This is an open access article distributed under the Creative Commons Attribution License, which permits unrestricted use, distribution, and reproduction in any medium, provided the original work is properly cited.

\begin{abstract}
The paper presents a new method of stiffening CHS L-joints and compares it against current stiffened and unstiffened moment connections. The method is derived from studying the failure modes of existing methods, typically local buckling and ovalisation of the section. Unstiffened right-angled CHS connections have been shown to be weak due to local buckling and ovalisation. Stiffing plates placed across the joint can increase the moment capacity of the section by preventing ovalisation of the section but is architecturally unsightly. An alternative approach, where a stiffening plate welded vertically inside both the column and beam, outperformed the unstiffened frame plate in terms of reduced ovalisation and increased load capacity. It was also found to perform better than the stiffened connection in terms of both vertical and horizontal deflection. However, more research is required to ensure a fully restrained connection to satisfy codes of practice and constructible.
\end{abstract}

\section{Introduction}

Circular hollow section (CHS) connections have been extensively researched [1-4] due to their frequency in different structures, including trusses, portal frames, light roofs, fairgrounds, and some bridges. The above research has demonstrated that CHS moment connections were weak and various strengthening techniques were considered including changing the support conditions and the angle of the joint connection.

CHSs are being used more and more in steel construction as they are suited to provide lateral support elements to resist wind, water, or wave loading. Its architecturally attractive shape allows it to remain visible in finished structures instead of being boxed out as is the case for most steel columns and beams. They are structurally efficient as columns due to their symmetrical nature (no weaker axis) and offer better corrosion resistance due to an absence of sharp edges.

This paper presents the performance of stiffened and unstiffened CHS L-joints (designed in accordance with Eurocode $3[1,5])$ until failure. Previous research $[1-4,6]$ has showed that stiffening plates in the joint increase the moment capacity by 40 to $60 \%$ by allowing the full plastic moment capacity to be reached depending on the diameter to thickness $(D / t)$ ratio. However, transverse stiffening plates are not very aesthetically pleasing so an alternative method for stiffening the joint is proposed to resist the failure mechanisms observed using an internal stiffening plate welded inside both the beam and column.

\section{Review of Previous Literature}

Mang et al. [4] investigated the load bearing behaviour of CHS L-joints to determine a method to design the connection for both unstiffened and stiffened members, as shown in Figures 1(a) and 1(b), respectively. The design of CHS Ljoints was undertaken using DIN 18808 [7] where a reduction factor $(\alpha)$ is used to account for the bearing capacity of an unstiffened L-joint. The stiffened connection was designed as a moment loaded beam with the stresses not exceeding allowable limits. Load tests were undertaken on twenty specimens (10 stiffened and 10 unstiffened) with different $D / t$ ratios. The lengths of the members were five times the external diameter with a $15 \mathrm{~mm}$ thick transverse plate added to the joints of the stiffened frames. Following tests to determine the ultimate tensile capacity, the sections were classed in accordance with Gardner and Nethercot [5]. The results found that stiffened specimens maintained the original cross section at the joint and acted as a moment loaded beam [8]. A plastic deformation failure mechanism was observed in the compression 


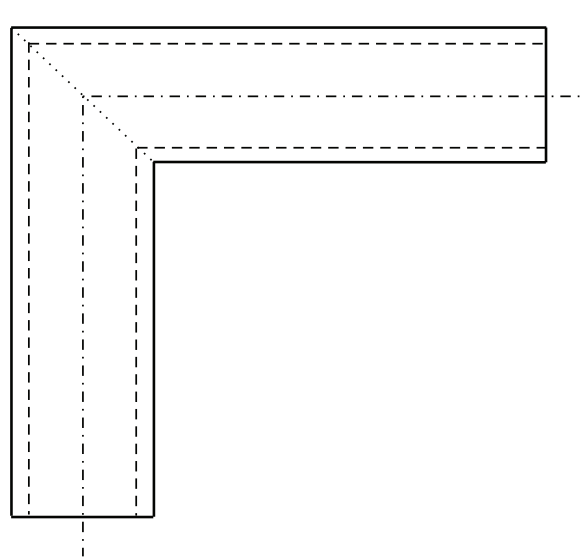

(a)

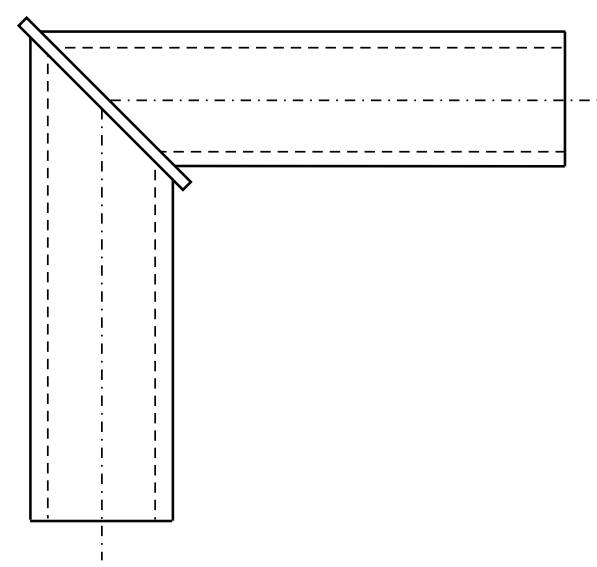

(b)

FIgURE 1: (a) Unstiffened and (b) stiffened CHS L-joints.

zone. The unstiffened connection created an ovalised cross section following testing with more predominant buckling failures occurring for larger $D / t$ ratios. Furthermore, the unstiffened connection generated a distinctive "shell" shape within the joint due to a lack of stiffness.

Before the above research was undertaken, design graphs for CHS were only available for grade S235/S355 steel and a limited range of $D / t$ ratios. It was recommended that, for safe design, the CHSs required $D / t$ of $\leq 40$ with any section $\geq 40$ be treated as a stiffened connection regardless of the ratio.

Research was undertaken by Karcher and Puthli [1] into the behaviour of CHS L-joints in bending with tension and compression on the inside corners. In total, 38 static tests with 12 different section geometries were used on stiffened and unstiffened connection with the influence of steel grade (S235 to S890) on the load bearing behaviour also investigated. The results found that stiffened L-joints reached the full plastic moment capacity and the cross section remained in place with no deformation as its stiffness was sufficient to prevent ovalisation as the whole cross section is available for the transmission of the bending moment. The unstiffened frame failed due to local buckling of the sides within the joint while still being within the elastic range with the full plastic moments not realised. The ultra-high strength steel (S890) failed in tension by brittle fracture. Tension loading could be continued until the formation of cracks with large unacceptable deformations [9]. The authors found that the bearing capacity of the unstiffened L-joints depends on the $D / t$ ratio and the steel grade.

Results from research undertaken to assess the influence of the L-joint connection angle [4] found only a minor effect (approximately 12\%) on the load capacity between $90^{\circ}$ and $135^{\circ}$. Opening and closing the angle increase the tensile and compressive stresses, respectively, between the beam and column.

\section{Experimental Programme}

3.1. Structural Details. Testing was carried out on three right-angled $168.3 \times 5 \mathrm{~mm}$ CHS S235 graded steel frames

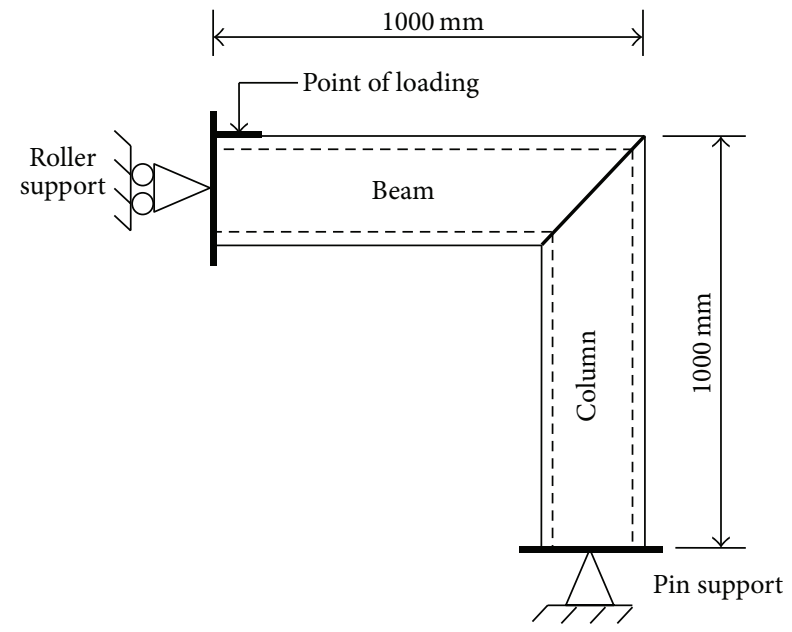

FIGURE 2: Schematic of the (unstiffened) CHS frame used for testing.

TABLE 1: Measured $168.3 \times 5 \mathrm{~mm}$ CHS section properties.

\begin{tabular}{lc}
\hline Diameter $(\mathrm{mm})$ & 168 \\
\hline Wall thickness $(\mathrm{mm})$ & 4.66
\end{tabular}

( $1 \mathrm{~m}$ horizontally $\times 1 \mathrm{~m}$ vertically) as shown in Figure 2 . These lengths were used to suit the height restriction of the testing frame. While the authors acknowledge that these dimensions are relatively small for this type of connection, the behaviour of the connection will still yield useful findings. The support conditions consisted of a pinned based with a horizontal roller support where the vertical load was applied. The sections were welded together using a $5 \mathrm{~mm}$ butt weld (the ends of the CHS were chamfered to permit better penetration and connection). Measured sectional properties of the steel used are shown in Table 1. 


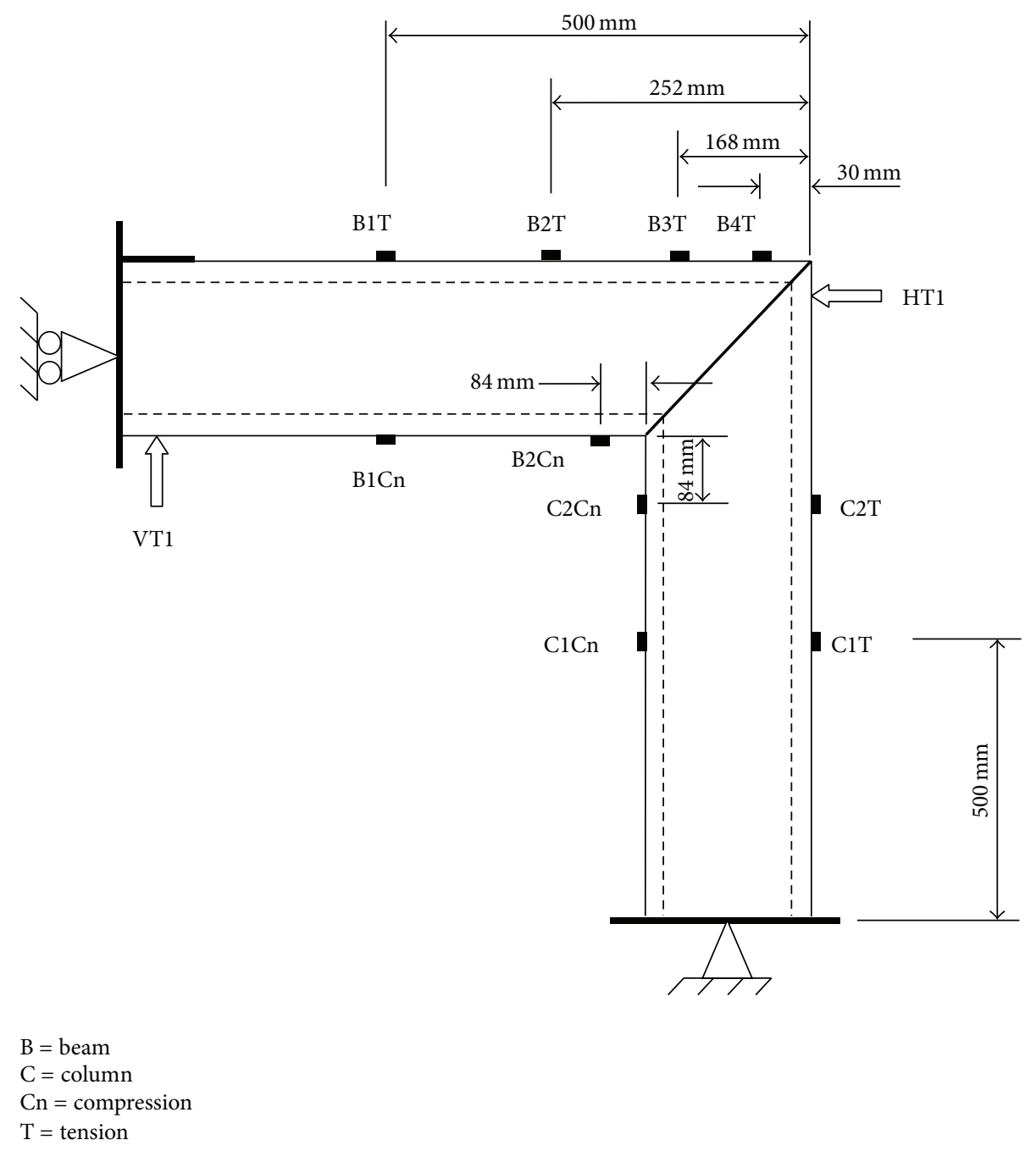

FIGURE 3: Instrumentation placed onto the testing frames.

3.2. Measurement of Deformations and Strains. Each frame was fitted with two external linear transducers (VT1 and HT2) to monitor deflections during loading. Four strain gauges were placed on opposite sides at midpoint along the beam (B1T and $\mathrm{B} 2 \mathrm{Cn}$ ) and column (C2T and $\mathrm{C} 4 \mathrm{Cn}$ ) to record strains in the tension and compression zones, respectively. Four strain gauges are placed at $84 \mathrm{~mm}$ (half the CHS diameter) from the interior edge of the connection on opposites sides in both sections (B3T, C5C, and C6T) to monitor the applied moment which was expected to undergo local buckling. Two more strain gauges were placed on the top face of the beam at 30 and $252 \mathrm{~mm}$ from the connection (B4T and B5T) to observe the strains around the connection and compare the behaviour in the three sections being tested. Figure 3 shows the layout of the instrumentation on the frame.

3.3. Material Testing. The material properties determined included Young's modulus of the steel and the maximum tensile capacity, both in accordance with ISO 6892 [10].
3.3.1. Young's Modulus. Young's modulus was determined using a $300 \mathrm{~mm}$ long $\times 22 \mathrm{~mm}$ wide $\times 4.66 \mathrm{~mm}$ thick $(\mathrm{S} 235)$ sample of the CHS. Strain gauges were attached to both sides of the plate and positioned into a Denison tensile machine. A preliminary tensile force was applied not exceeding $5 \%$ of the expected yield strength. The tensile load was applied in increments of $1 \mathrm{kN}$ up to $10 \mathrm{kN}$ (to ensure that it remains in the elastic region of the steel) with the strain at each load increment recorded and stress calculated.

3.3.2. Tensile Failure Test. The tensile failure test was carried out using an identical plate. Strain gauges were not fitted as they would be subject to excessive elongation so only the load and the distance between the tension jacks before and after the test were recorded.

\subsection{Frame Load Tests}

3.4.1. Unstiffened Frame. The load was applied $75 \mathrm{~mm}$ from the support onto end plate on the beam. A vertical stiffening 


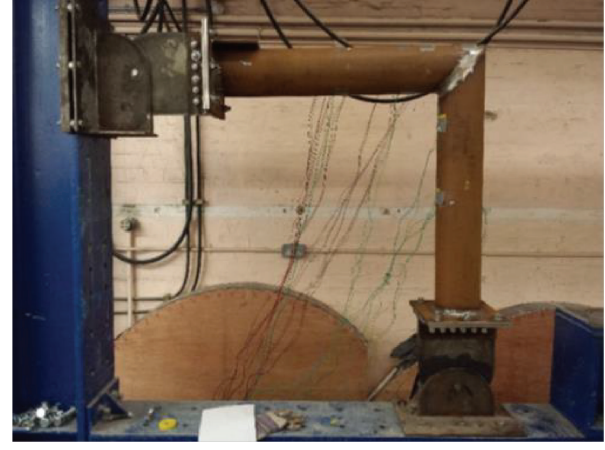

FIGURE 4: Unstiffened frame before testing.

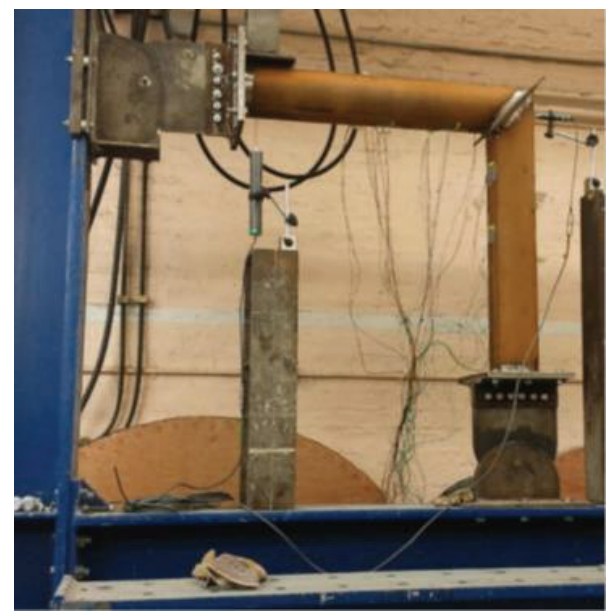

Figure 5: Stiffened frame before testing.

plate was welded inside the CHS under the point of loading to prevent the cross section deforming during testing. The unstiffened frame before testing is shown in Figure 4.

3.4.2. Stiffened Frame. This frame is identical to the unstiffened but had a $10 \mathrm{~mm}$ thick stiffening plate positioned at a $45^{\circ}$ angle across the beam-column connection. A $5 \mathrm{~mm}$ fillet weld was used to make the connection between the beam, plate, and column. Figure 5 shows the stiffened frame in position before testing.

3.4.3. Alternative Stiffening Design. This alternative approach was designed to increase the moment capacity across the joint and decrease the likelihood of ovalisation, improving the ability of the frame to transfer forces from the interior to the exterior faces while improving the aesthetics of the connection.

Therefore, two vertical stiffening plates (Figure 6), sufficient to resist the compressive forces, were welded $90 \mathrm{~mm}$ into the beam and column separately to provide a direct path for the forces to transfer between faces and prevent the section from narrowing and deforming during loading. The orientation of the plate was parallel to the applied load vertical which is optimal to transfer compression forces; otherwise the section would tend to bulge along the neutral axis and go into tension. This approach also makes the installation of the plate easier.

Two linear strain gauges were placed on opposite sides of the stiffening plate $50 \mathrm{~mm}$ from the base to monitor the compressive strains and if it deformed during loading. The two external transducers (one located each side of the connection) monitored if ovalisation did occur. Figure 6(b) shows the frame in position.

\section{Experimental Results}

4.1. Young's Modulus. Figure 7 shows the stress-strain relationship for the CHS sample. The slope of the straight line determined Young's modulus to be $168 \mathrm{GPa}$.

4.2. Tensile Failure Load. Figure 8 shows the results of the tensile failure test. Taking $21.6 \mathrm{kN}$ as the point at which the plate begins to yield and using the value for Young's modulus and the cross-sectional area, the yield stress and strain can be calculated as $263 \mathrm{~N} / \mathrm{mm}^{2}$ and 0.00156 using (1) and (2), respectively, where $\sigma_{y}$ is the yield stress $\left(\mathrm{N} / \mathrm{mm}^{2}\right), F_{t}$ is the maximum elastic tensile force $(\mathrm{N}), A_{m t}$ is the cross-sectional area of the test specimen, and $\epsilon_{y}$ is the yield strain:

$$
\begin{aligned}
\sigma_{y} & =\frac{F_{t}}{A_{m t}}, \\
\epsilon_{y} & =\sigma_{y} E .
\end{aligned}
$$

\subsection{Unstiffened Frame Load Results}

(i) Load-Deflection Results. Test 1 failed at an ultimate applied load of $14 \mathrm{kN}$ as may be seen in Figure 9. The load-deflection results for the vertical and horizontal axis are shown in Figure 10. As shown, the frame deflects with the application of load until failure with deflections of approximately $58 \mathrm{~mm}$ vertical and $10 \mathrm{~mm}$ horizontal.

(ii) Strain Results. Figure 11 presents the change of strain in the frame during testing. As may be seen, there are higher strains in the column due to the additional axial compressive force in the beam. The greatest strains were recorded in the central areas of the frame ( $\mathrm{ClCn}$ and $\mathrm{ClT} ; \mathrm{B1Cn}$ and $\mathrm{B1T})$ due to the deformations causing ovalisation of the section. While deformation was greater around $\mathrm{B} 2 \mathrm{~T}, \mathrm{C} 2 \mathrm{Cn}$, and $\mathrm{C} 2 \mathrm{~T}$, due to the higher strains resulting from the bending moment, the steel was reducing in cross section leading to complicated stress concentrations and alternative force paths through the connection [11]. Evidence of ovalisation is shown by the changes in strain behaviour at high moments.

In B3T, a compressive stress was observed throughout testing and was maintained as the applied moment and axial compression forces combined to produce higher strains close to the joint, which is expected. No recorded strains reached the yield point $(0.00156)$ because the deformations of the sections made them incapable of carrying load and therefore fail with excessive deflections. 


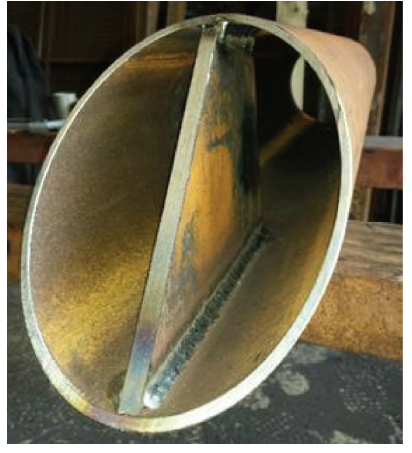

(a)

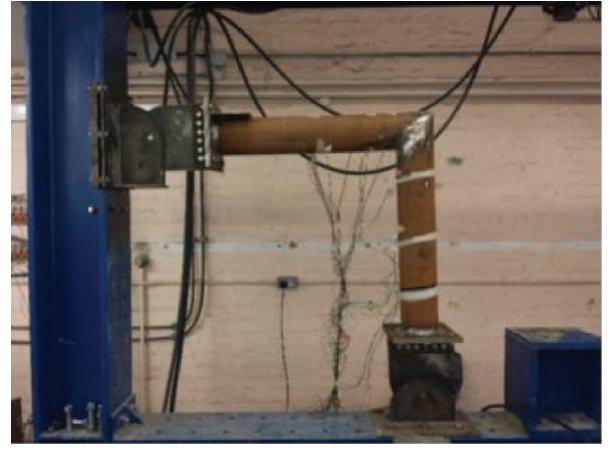

(b)

FIgURE 6: (a) Stiffening plate welded into the CHS and (b) the alternative frame in position before testing.

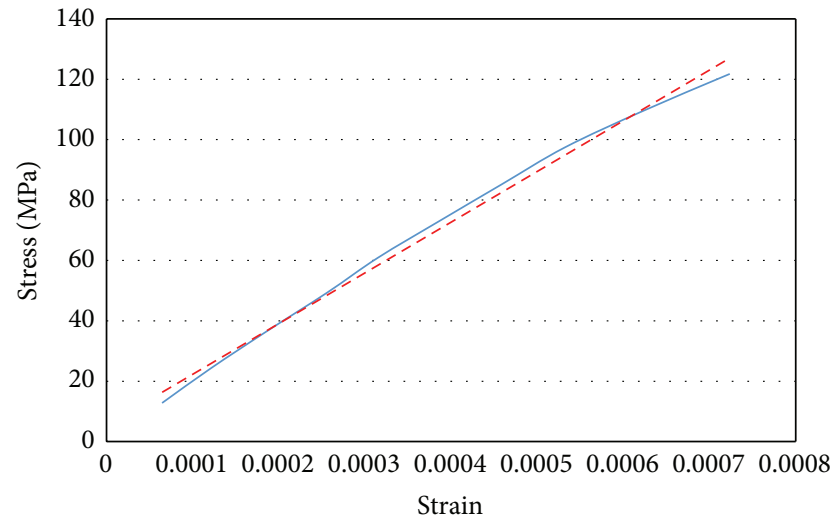

Figure 7: Slope of stress-strain to determine Young's modulus for the steelwork.

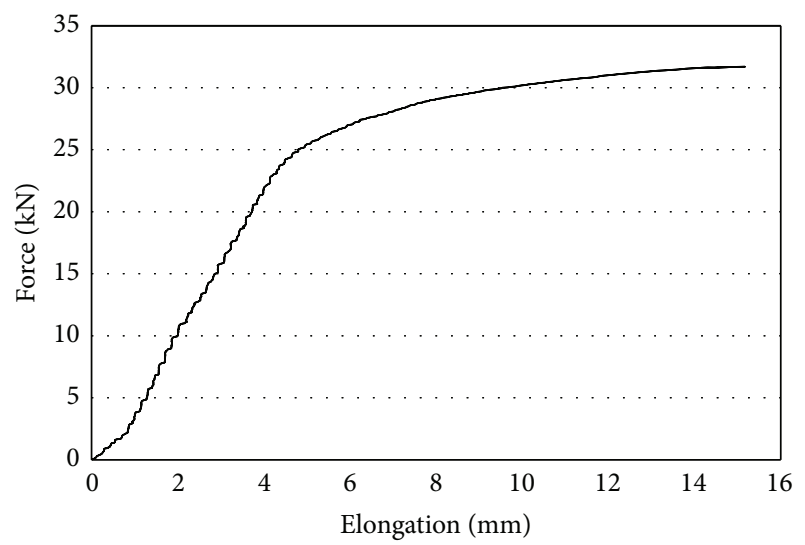

FIGURE 8: Force and elongation relationship results from the tensile test.

The two gauges located close to the joint (B2Cn and $\mathrm{C} 2 \mathrm{Cn}$ ) demonstrate that the strain behaved as expected along the assumed tension zone near the connection (see Figure 12). Gauge B3T shows a reduced strain which is due to the deformations near the connection. The bulging behaviour of the section is greatest in this area with the forces, due

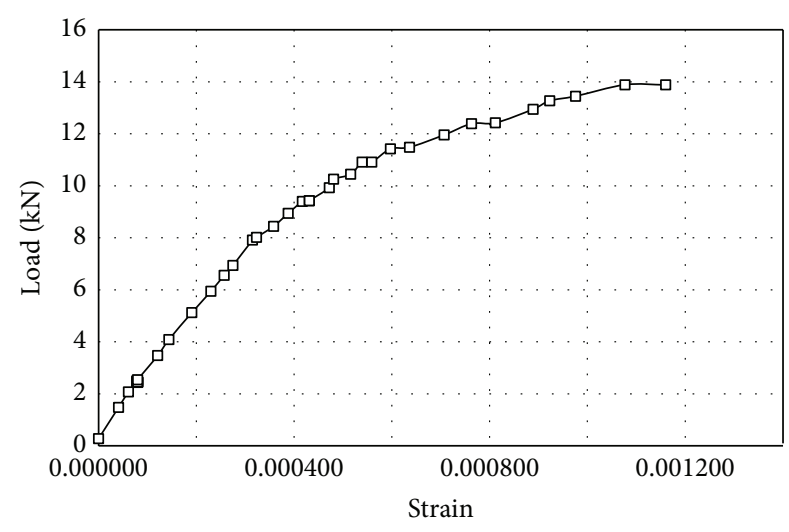

FIGURE 9: Load versus strain results for the unstiffened frame.

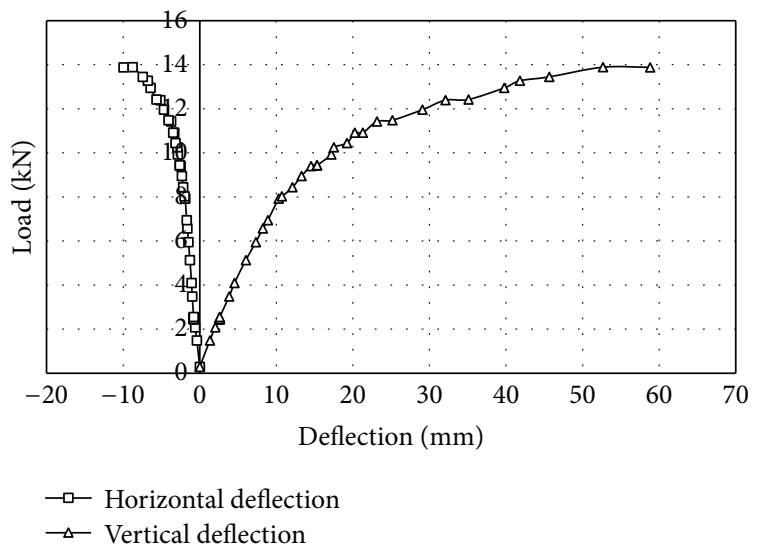

FIGURE 10: Load versus deflection results for the unstiffened frame.

to ongoing bending and tension, following a different path through the section.

(iii) Physical Findings. In the beam, the highest deformation in the cross section occurred from midway to the connection due to ovalisation $(6 \mathrm{~mm}$ and $9 \mathrm{~mm}$ vertically and horizontally, respectively, at midpoint and $16 \mathrm{~mm}$ at the connection along the neutral axis). In the column, deformations began at $400 \mathrm{~mm}$ from the base due to the higher compression 


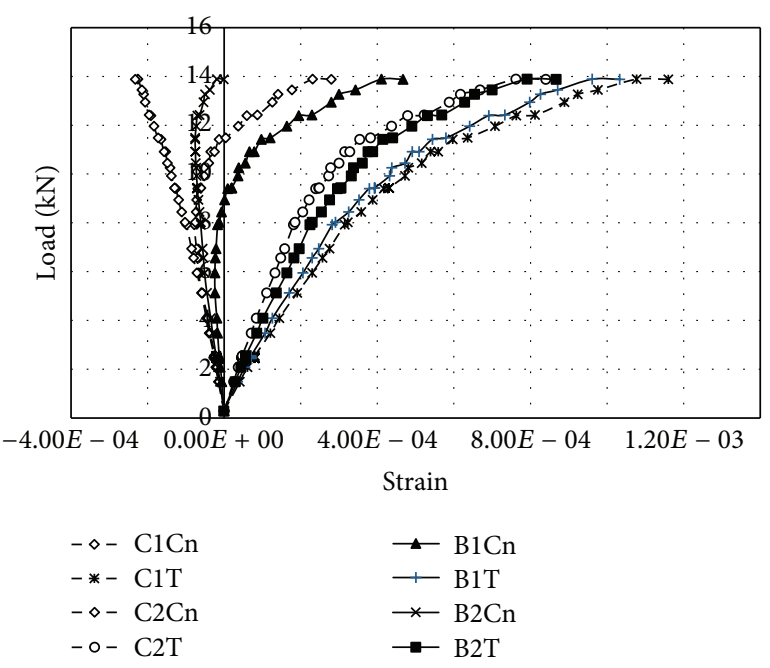

FIGURE 11: Load/strain results for the unstiffened frame.

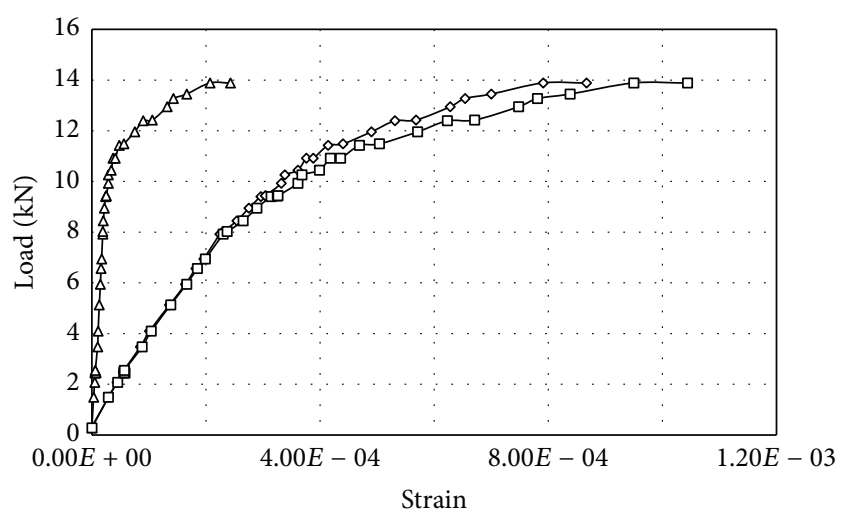

$\leadsto$ B2T

$\triangle \mathrm{B} 3 \mathrm{~T}$

$\rightarrow$ B $-\mathrm{T}$ T

FIGURE 12: Load/strain results for the gauges close to the connection.

force than in the beam where the cross section narrowed to $159 \mathrm{~mm}$. Figure 13 shows the extent of deflection under the applied load. When the load was removed the section did recover, returning half the deflection observed at failure.

\subsection{Stiffened Frame}

(i) Load-Deflection Results. The failure load for the stiffened frame was $55 \mathrm{kN}$. The load-deflection results (Figure 14) indicate that the frame deflected linearly during loading with a deflection of $18 \mathrm{~mm}$ at $43 \mathrm{kN}$ where it became nonlinear and deflection increases considerably until failure. Horizontal deflection is minimal ( $6 \mathrm{~mm}$ Figure 15) which was expected as the stiffening plate reduced the sections tendency to ovalise.

(ii) Strain Results. Figure 16 shows the strain readings from the 8 gauges placed around the frame. The exterior strain gauges (B1T-B4T and C1T-C2T) confirm that the outer sides of the CHSs were in tension during testing. At $46 \mathrm{kN}$, ClT and $\mathrm{C} 2 \mathrm{~T}$ show a rapid increase in strain which indicates that the steel was deforming before yielding at these locations. At the failure load, C2T recorded a strain of 0.00156 which was found to be the yield strain of the CHS.

Figure 17 presents the strain measurements of the gauges (B2T-B4T) attached to the beam near the joint. As may be seen, $\mathrm{B} 2 \mathrm{~T}$ and $\mathrm{B} 3 \mathrm{~T}$ recorded strains indicating that the frame shared the load along the exterior tension face which confirms a stiffer joint due to the plate. This also allowed the strains to be transferred throughout the walls of the CHSs rather than through the tension and compression faces.

(iii) Physical Findings. Although no ovalisation was observed near the joint, it was detected further along the column. No visible deformations occurred in the beam which is due to higher axial compressive forces [12] acting on the column which led to the ovalisation mentioned previously. The column deformation was observed at midheight with the cross section narrowing to $164 \mathrm{~mm}$ vertically and bulging to $174 \mathrm{~mm}$ horizontally, creating a dimple. This dimple is caused by the column deforming inwards as the section narrowed during loading. Upon further loading, this dimple effect continued causing the column to fold in on itself.

4.5. Alternative Stiffened Frame. The above results have demonstrated that the moment capacity of the unstiffened frame is much less than the stiffened. Indeed, both frames moment capacities are quite low when one considers their axial capacity (hence the use of CHS as axial members in structures). Considering the observed failure modes of both frames, an alternative stiffening method was proposed to prevent these failure modes and surpass the load capacity of the stiffened section. In the unstiffened frame, the observed mode of failure was ovalisation of the cross section due to the connection being unable to transfer the forces from the interior to exterior faces directly. The section therefore bulged creating the ovalisation seen above.

Therefore, a stiffening plate welded within the section providing a direct force transfer between faces and should also prevent the section from narrowing and deforming during loading (provided it can resist the compressive forces transferred to it). The orientation of the plate was parallel to the applied load so it only had to transfer the compression forces. If it were perpendicular to the loading, the cross section would bulge along the neutral axis, requiring it to go into tension to maintain the cross-sectional area. Although steel performs better in tension, the weld would have to be able to withstand these tensile forces. The failure modes observed suggest the optimum way to prevent them is using a vertical stiffening plate welded inside the section following the $45^{\circ}$ angle of the connection and welded to both sides of the CHS (compression and tension faces). This will increase the compressive resistance which would have to be transferred through the walls of the section. However, it is not physically possible to weld the plates to one another inside the closed connection (thus providing a $252 \mathrm{~mm}$ unrestrained length that could buckle under compression which is unlikely due to the plate's high moment capacity).

As seen already, local buckling occurred $60 \mathrm{~mm}$ below the joint in the column due to the higher axial force present. 


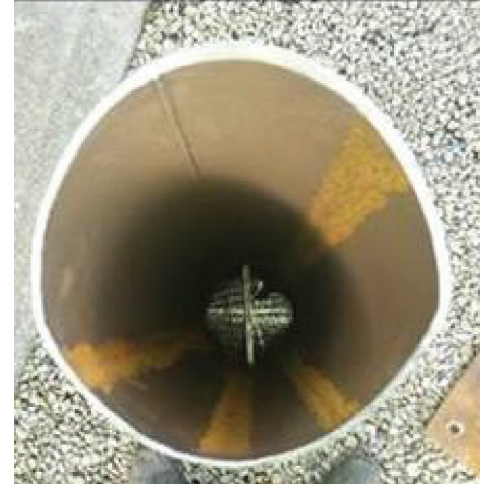

(a)

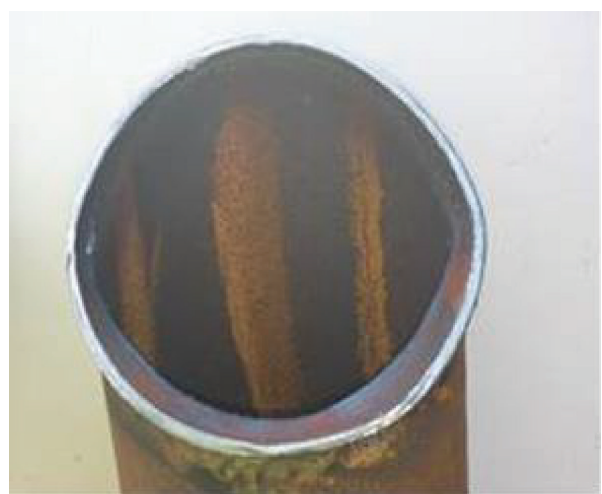

(b)

FIgURE 13: (a) Deflected frame and (b) buckling and folding along the connection.

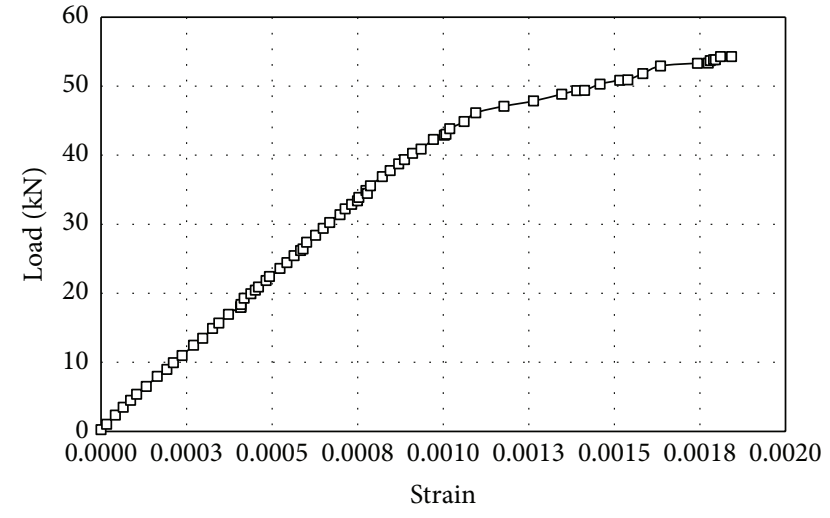

FIGURE 14: Load-strain results for the stiffened frame.

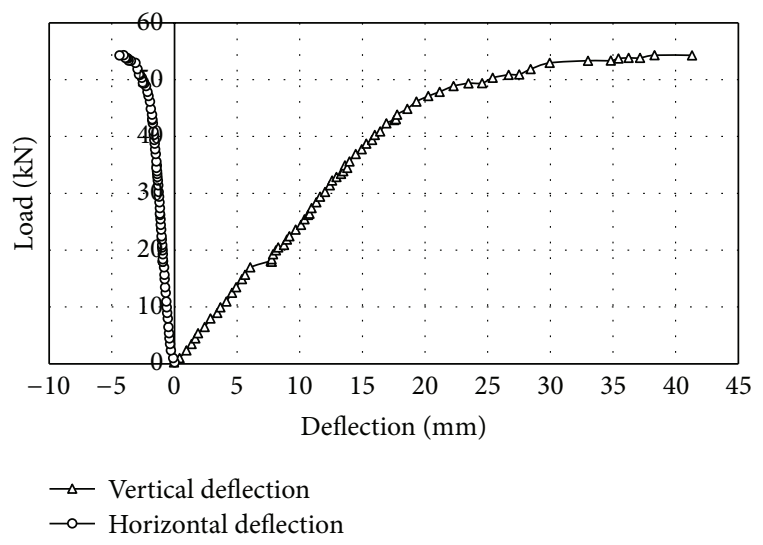

FIGURE 15: Load-deflection results for the stiffened frame.

To prevent this, the plate was extending beyond the point at which the dimple formed, reducing the likelihood of ovalisation.

A similar monitoring system was employed as the previous frames with two additional strain gauges (Figure 18(a)) placed on both sides of the interior stiffening plate in the column section $50 \mathrm{~mm}$ from the base. These gauges

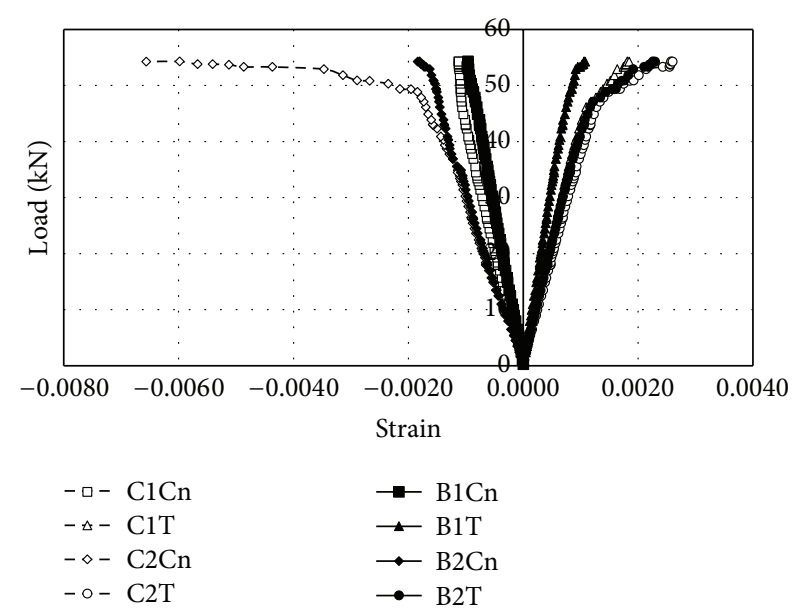

FIGURE 16: Load-strain results for the 8 strain gauges fixed onto the stiffened frame.

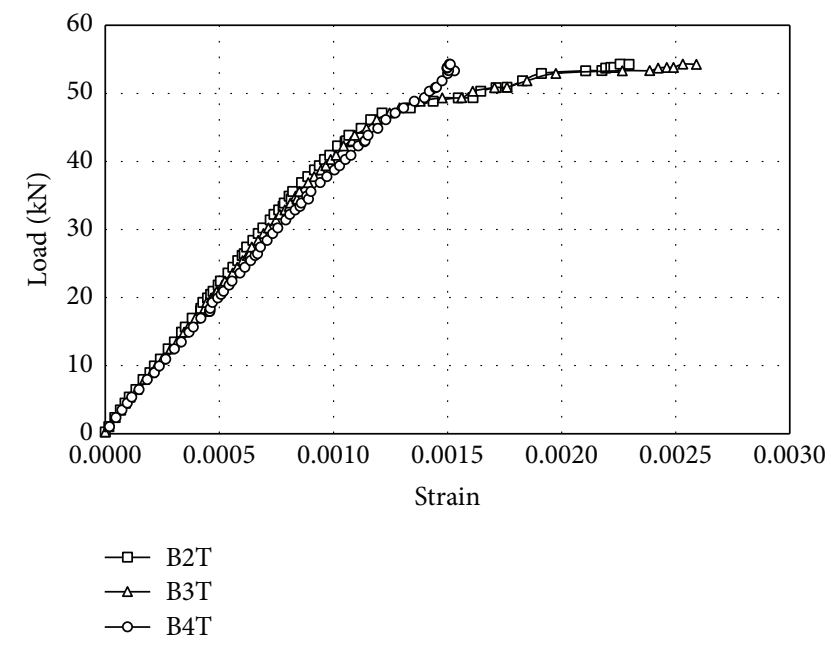

FIGURE 17: Strain measurements for gauges B2T, B3T, and B4T.

monitored the compression in the plate during loading and to highlight if it deformed during testing. Two additional 


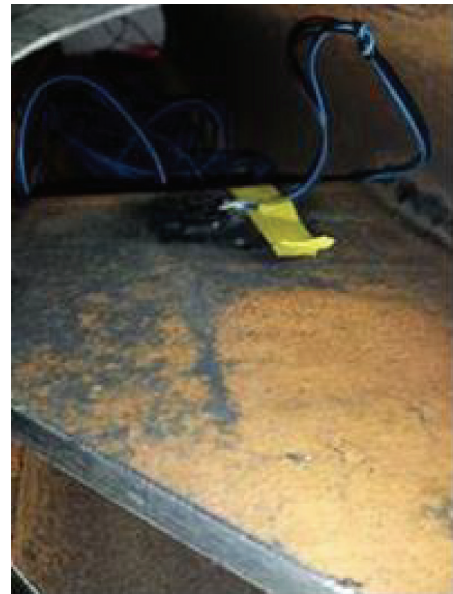

(a)

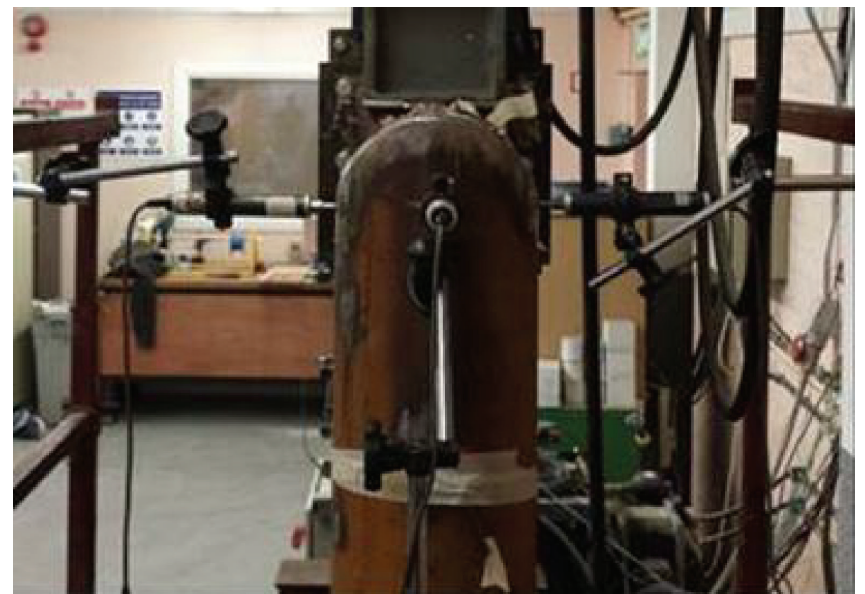

(b)

FIGURE 18: (a) Additional strain gauges and (b) transducers placed onto the alternative design.

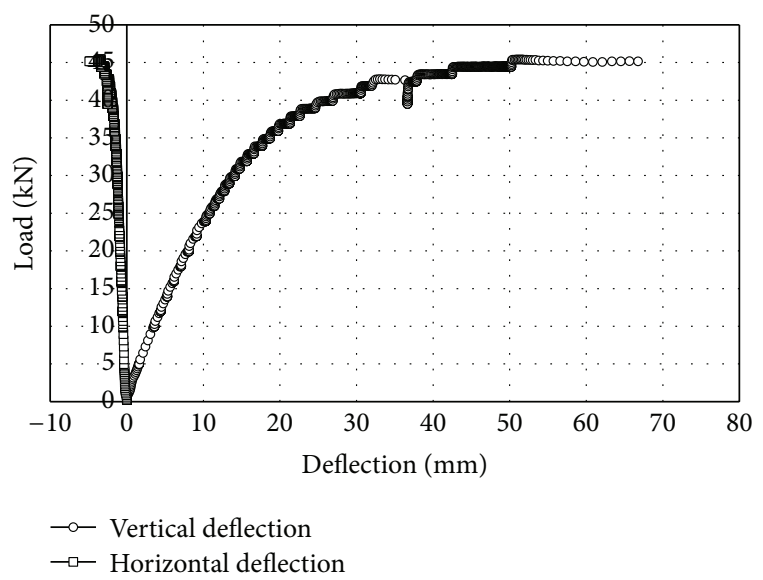

FIGURE 19: Load-deflection results for the alternative stiffening design.

transducers (Figure 18(b)) were placed on either side of the connection to record the effect of ovalisation.

(i) Load-Deflection Results. The ultimate failure load of the new stiffened section was $45 \mathrm{kN}$ with a deflection of approximately $68 \mathrm{~mm}$ (see Figure 19). There was still some minor ovalisation but much less than that seen in the unstiffened section. The plates also managed to reduce the horizontal deflection of the section to approximately $4 \mathrm{~mm}$, as shown in Figure 19.

(ii) Strain Results. Figure 20 shows the results of 7 of the linear strain gauges, as B2T broke during testing. Strains were linear until approximately $40 \mathrm{kN}$ where the steel began to yield in compression. It should be noted that, in the stiffened frame, a dimple had started to form at this point but did not occur here due to the interior stiffening plate. The results show that the strains recorded in the column were higher than the beam with those strains at midpoint greater than gauge $\mathrm{C} 2 \mathrm{~T}$. This is believed to be due to the weld connecting the plate and

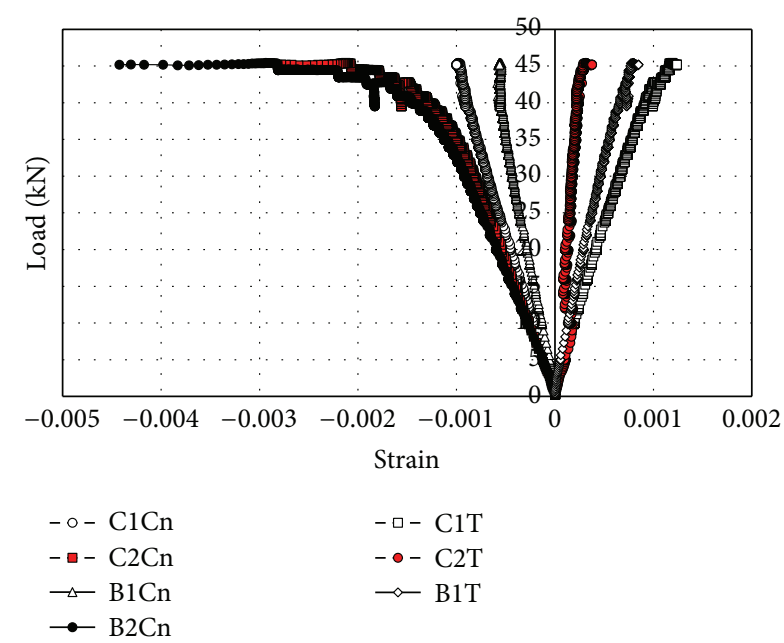

FIGURE 20: Strain measurements for the alternative stiffening design.

the section reducing the stress on the CHS which also confirms the high strains.

The strains recorded, on average, were lower than those in the stiffened frame with gauge B4T being significantly higher result at failure. This is due to the weld failing and steel deforming. Gauge B3T recorded sporadic results due to the interior stiffening plates not welded together which would have transmitted greater tensile forces from the beam to the column [13].

The results from the two additional transducers to measure the ovalisation of the section are shown in Figure 21. Both should show negative results as the section was bulging outwards and therefore increasing the diameter. To determine the actual amount of ovalisation at this location, the two results were added to produce Figure 22 which represents the change in length of the major axis and demonstrate a linear increase in deformation $(1.1 \mathrm{~mm}$ at $38 \mathrm{kN})$ as the interior plate was preventing ovalisation. 


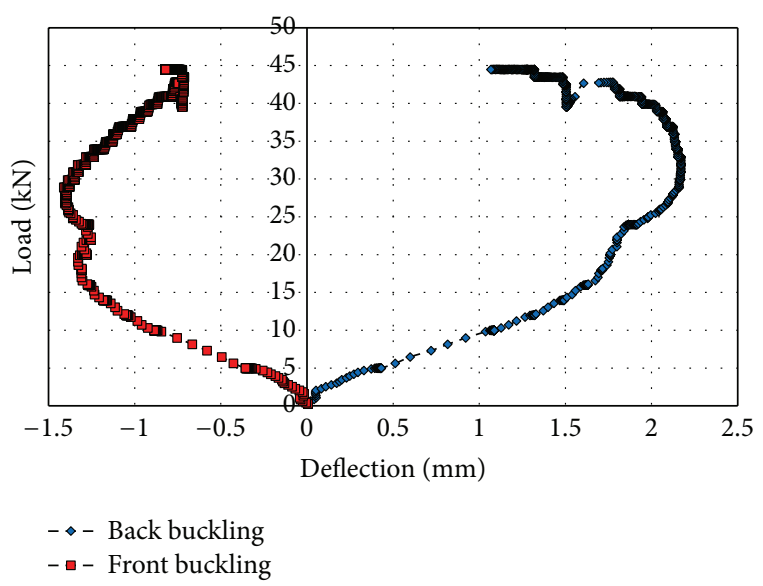

FIGURE 21: Ovalisation results for the alternative design.

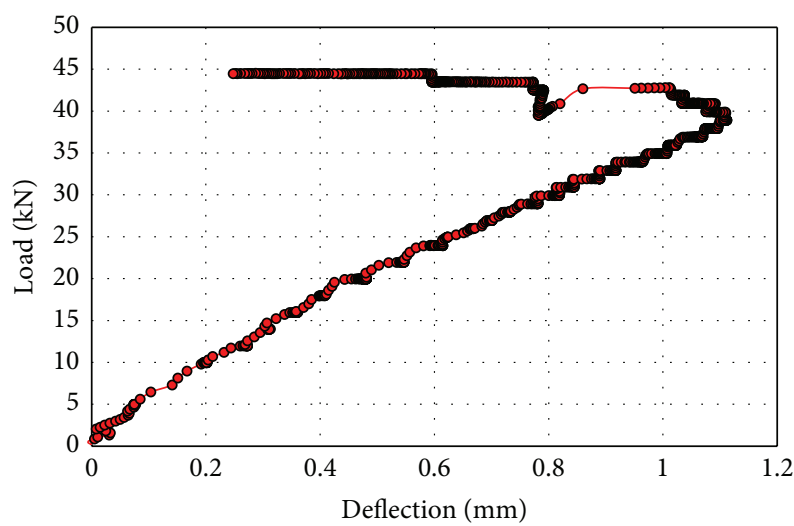

FIgURE 22: Cumulative increases in section diameter.

Figure 23 shows the strain measurements in the stiffening plate within the column. The results show that the plate experienced a bending moment as well as the expected compressive force. However, the strains are much lower than the yield value so bending had no significant influence on the plate's performance.

\subsection{Comparison of Stiffening Methods}

(i) Load-Vertical Deflection. Figure 24 summarises the loaddeflection curves for the three frames. As may be seen, the unstiffened frame did not sustain much load before failure (approximately $14 \mathrm{kN}$ with a deflection of $75 \mathrm{~mm}$ ). The load capacity is much less than the other frames which had similar ultimate loads (48 and $54 \mathrm{kN}$ ) and deflections (65 and $60 \mathrm{~mm}$ ) upon failure.

(ii) Horizontal Deflection. The unstiffened frame did horizontally deflect more at failure (see Figure 25) than the alternative design confirming that the interior stiffening plates reduced this greatly. It also had less horizontal deflection that the conventional stiffened frame up to approximately $30 \mathrm{kN}$.

(iii) Strain at Joint. From Figure 26, it can be seen that the conventionally stiffened frame failed with a strain beyond

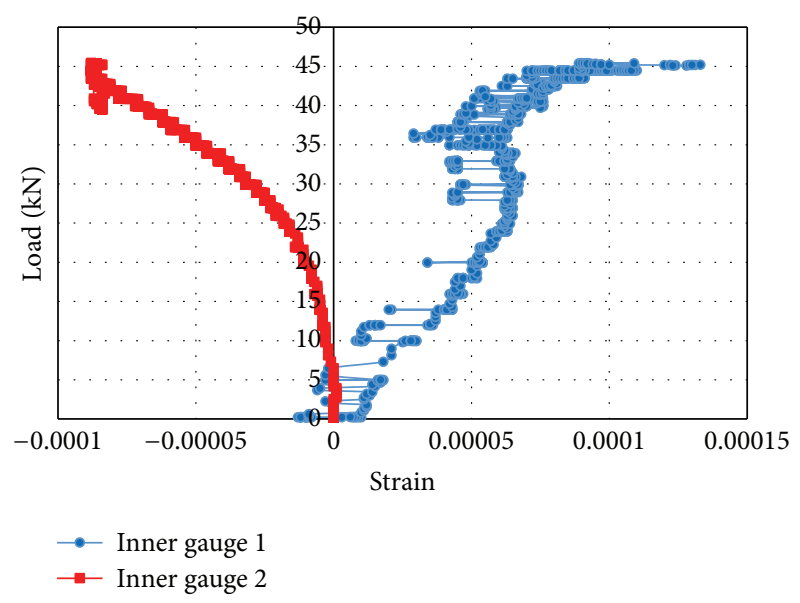

FIgURE 23: Measured strain from the column internal stiffening plate.

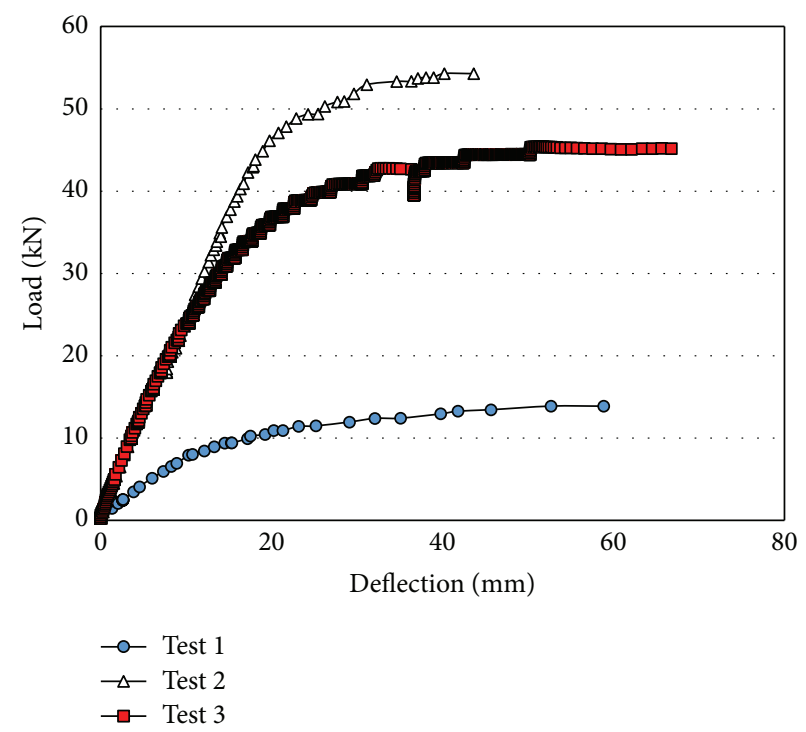

FIGURE 24: Load-vertical deflection curves for the three frames.

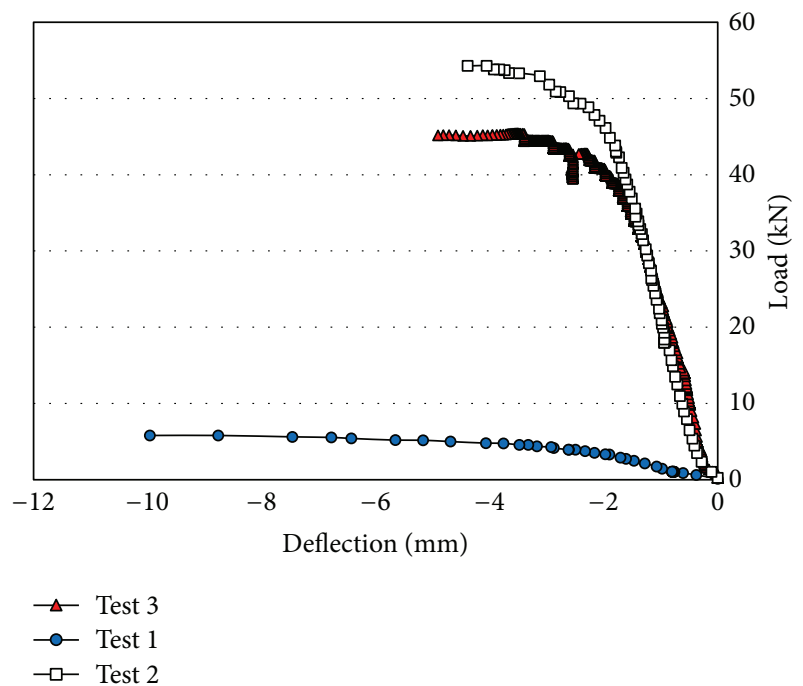

FIGURE 25: Load-horizontal deflection curves for the three frames. 


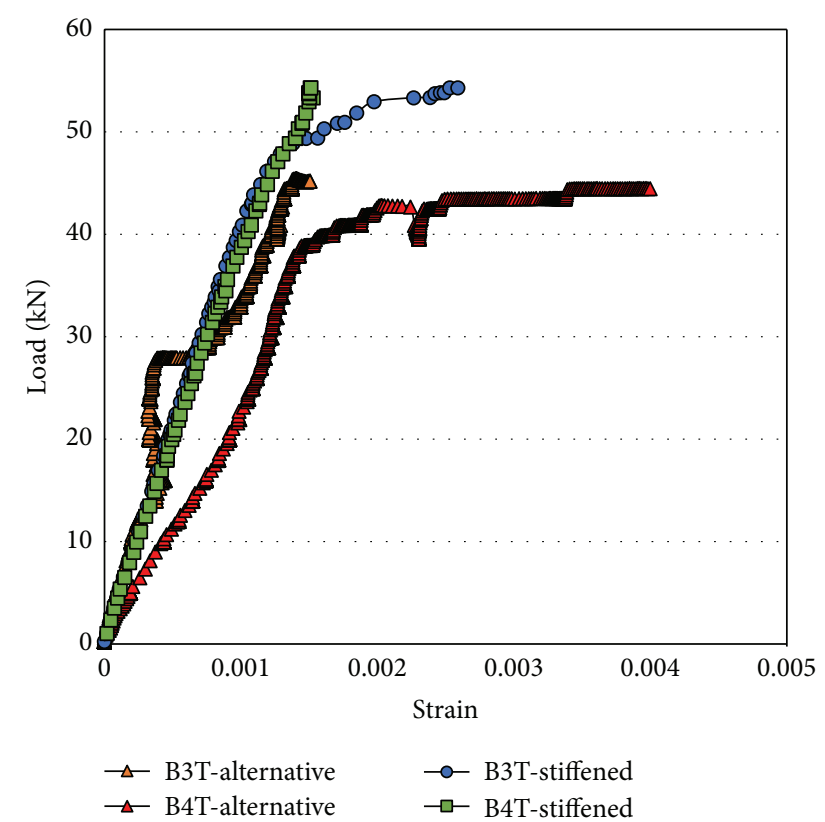

Figure 26: Strain measurements at the joint for the three frames.

the yield point (0.00156) with $\mathrm{B} 4 \mathrm{~T}$ in the alternative design failing dramatically at this point with the section pulling apart during testing. The recorded strains in the alternative design were quite irregular, indicating the section experienced complicated concentrations in some areas whereas in the conventional frame, the stresses appeared linear until failure load.

4.7. Summary. After testing it was clear that the interior stiffening plates are an effective method of stiffening a CHS L-joint. While the failure load for the conventionally stiffened frame was higher, the deflection was beyond acceptable serviceability limits. While the new stiffening approach presented here did reduce ovalisation effects, it is difficult to achieve a strong welded connection to resist the high tensile stresses placed on the plate. However, the stresses at which this would be a problem are quite high and as shown here only existed after the frame has undergone unpractical deflections at twice the capacity of the section. Notwithstanding this, it is an area where further research is required.

\section{Conclusions}

This project investigated the modes of failure of standard CHS L-joint connections. The results show that the unstiffened frame performed poorly in terms of stiffness with ovalising effects occurred in over $50 \%$ of the connection, a common flaw with CHS moment connections. A second frame using a conventional stiffening approach (a plate positioned $45^{\circ}$ across the joint) did ovalise slightly with local effects the cause for failure without reaching its plastic moment capacity.

An alternative design was investigated which is comprised of a stiffening plate welded vertically inside both the column and beam. This connection is more aesthetically pleasing and the results found that it outperformed the unstiffened frame significantly reducing ovalisation and increasing the load capacity. This connection also performed better than the standard stiffened connection as failure of the latter only occurred after significant deflection which would be beyond serviceability limits. The alternative design performed better in resisting horizontal deflection too.

Current design criteria require that the joint must be fully restrained against ovalisation in all axes with the alternative here offering restraint along one (vertical). Placing a second plate to satisfy these criteria requires more research.

\section{Competing Interests}

The authors declare that they have no competing interests.

\section{References}

[1] D. Karcher and R. Puthli, "The static design of stiffened and unstiffened CHS L-Joints, Tubular Structures IX," in Proceedings of the 9th International Symposium on Tubular Structures, pp. 221-228, Dusseldorf, Germany, 2001.

[2] J. Wardenier, Hollow Sections in Structural Applications, CIDECT, 1st edition, 2001.

[3] X. L. Zhao, T. Wilkinson, and G. J. Hancock, Cold-Formed Tubular Members and Connections, Elsevier Science, Oxford, UK, 2005.

[4] F. Mang, R. Puthli, and D. Karcher, "Investigations on stiffened and unstiffened L-Joints made of Circular Hollow Sections," in Proceedings of the 8th International Symposium on Tubular Structures (ISTS '97), Singapore, August 1997.

[5] L. Gardner and D. Nethercot, Designers' Guide to EN 1993-1-1 Eurocode 3: Design of Steel Structures-General Rules and Rules for Buildings, Thomas Telford, 2005.

[6] J. Wardenier, Y. Kurobane, J. A. Packer, G. J. van der Vegte, and X. L. Zhao, Design Guide for Circular Hollow Section (CHS) Joints under Predominantly Static Loading 1, CIDET, 2nd edition, 2008.

[7] DIN, "Stahlbauten, tragwerke aus hohlprofilen unter vorwiegend ruhender beanspruchung," DIN 18 808, Beuth, Berlin, Germany, 1984.

[8] L. Zhu, S. Han, Q. Song, L. Ma, Y. Wei, and S. Li, "Experimental study of the axial compressive strength of CHS T-joints reinforced with external stiffening rings," Thin-Walled Structures, vol. 98, pp. 245-251, 2016.

[9] M. Elchalakani, "A closed-form solution for elastic buckling of thin-walled unstiffened circular cylinders in pure flexure," ThinWalled Structures, vol. 80, pp. 120-129, 2014.

[10] ISO, "Metallic materials-tensile testing-part 1: method of test at room temperature," ISO 6892-1, International Organisation for Standardisation, 2009.

[11] W. M. Gho, F. Gao, and Y. Yang, "Strain and stress concentration of completely overlapped tubular CHS joints under basic loadings," Journal of Constructional Steel Research, vol. 62, no. 7, pp. 656-674, 2006. 
[12] Y. Chen, R. Feng, and C. Wang, "Tests of steel and composite CHS X-joints with curved chord under axial compression," Engineering Structures, vol. 99, pp. 423-438, 2015.

[13] W. Wang, Q. Gu, X. Ma, and J. Wang, "Axial tensile behavior and strength of welds for CHS branches to SHS chord joints," Journal of Constructional Steel Research, vol. 115, pp. 303-315, 2015. 


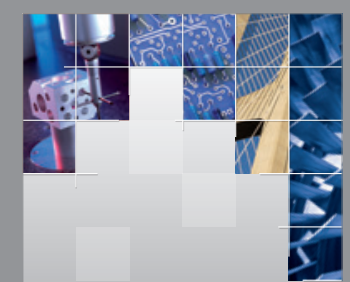

\section{Enfincering}
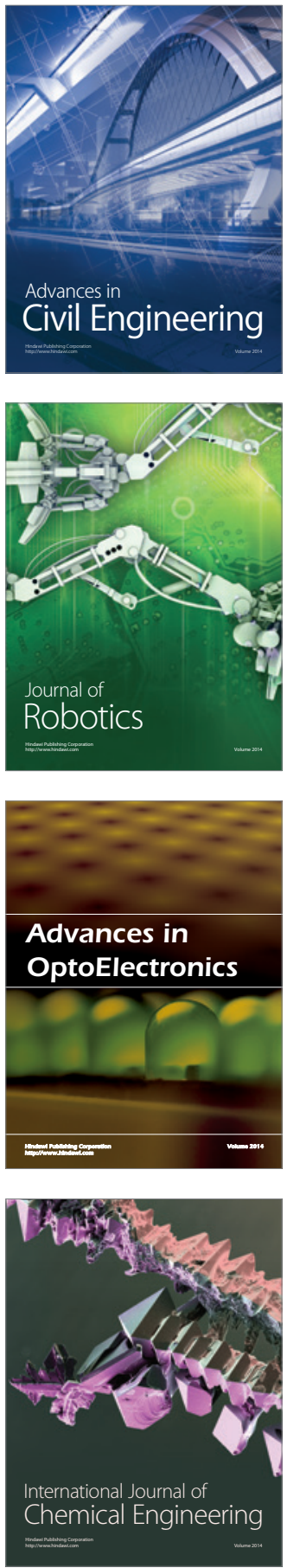

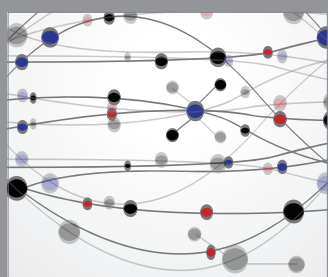

The Scientific World Journal

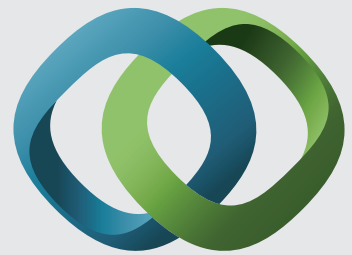

\section{Hindawi}

Submit your manuscripts at

http://www.hindawi.com
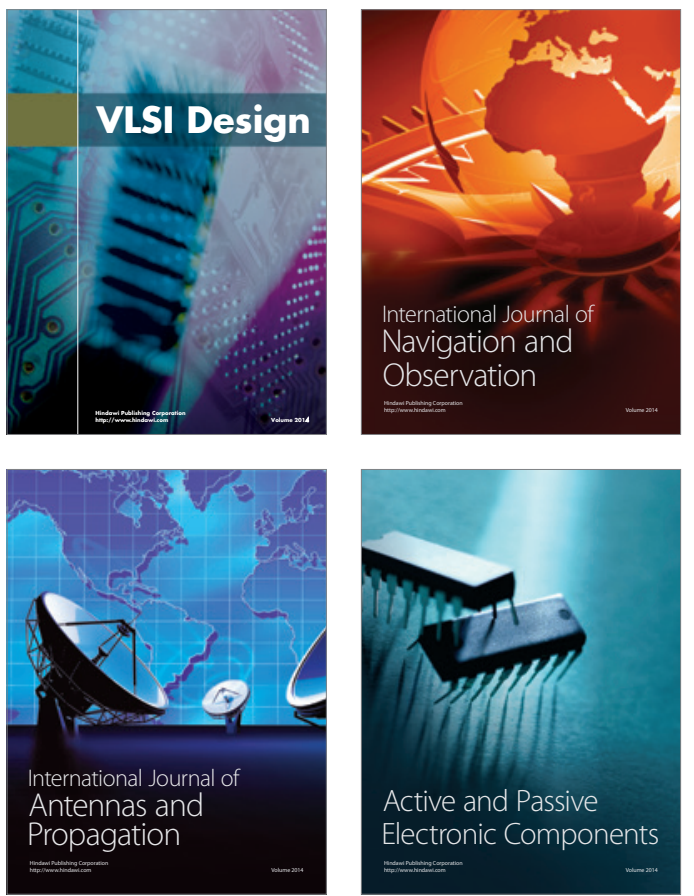
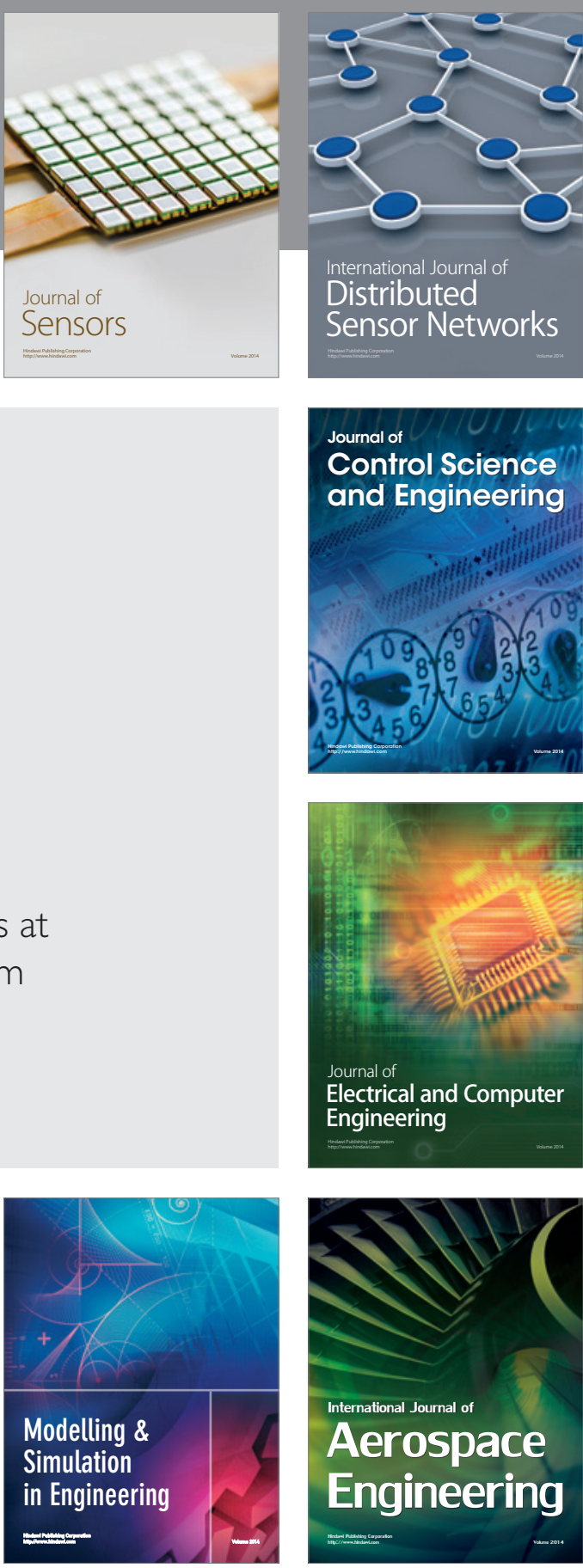

International Journal of

Distributed

Sensor Networks

Journal of

Control Science

and Engineering
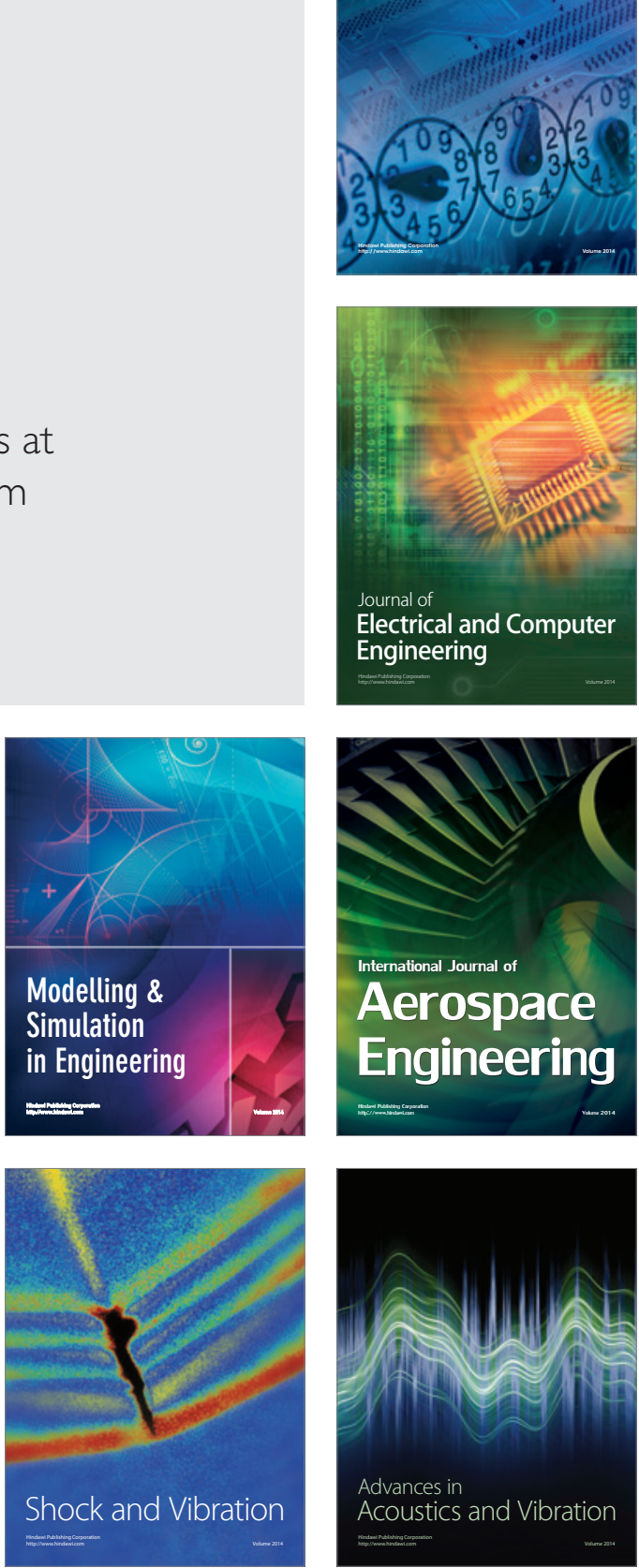